\title{
Tuberculous mastitis: a rare case report
}

\section{Hind Ennasser*, Jamal Eddine Raoudi, Hafsa Taheri, Hanane Saadi, Ahmed Mimouni}

Department of Obstetrics and Gynecology, Mohammed VI University Hospital Center, Oujda, Morocco

Received: 08 July 2020

Accepted: 05 August 2020

\section{*Correspondence:}

Dr. Hind Ennasser,

E-mail: hindennasser@gmail.com

Copyright: (c) the author(s), publisher and licensee Medip Academy. This is an open-access article distributed under the terms of the Creative Commons Attribution Non-Commercial License, which permits unrestricted non-commercial use, distribution, and reproduction in any medium, provided the original work is properly cited.

\section{ABSTRACT}

Tuberculous mastitis is a granulomatous mastitis due to infection by mycobacterium tuberculosis. It's a rare entity witch is often confused with breast carcinoma or pyogenic breast abscess because of its clinical and radiological aspect. The diagnosis is histological with identification of an epithelioid cell granulomas and necrosis. The treatment is based on anti-tuberculous therapy with a good clinical issue. Authors report a case of tubercular mastitis in a postmenopausal female diagnosed on adenectomy.

Keywords: Epithelioid cell granulomas, Granulomatous mastitis, Tuberculosis mastitis

\section{INTRODUCTION}

Breast tuberculosis is a rare form of extra-pulmonary tuberculosis even in endemic countries. Its prevalence has been estimated to be $0.1 \%$ of breast lesions examined histologically. ${ }^{1}$

It's often mimicking breast cancer or abscesses. Clinical awareness is necessary during diagnostic work-up for establishing the correct diagnosis and treatment. It typically affects young lactating multiparous women It is rare to see breast tuberculosis in a post-menopausal female as seen in the presenting case.

\section{CASE REPORT}

A 61 years old female, with history of lactation presented with a painless lump in her right axillary extension for 2 months duration and growth of mammary volume. There were no other complaints like fever weight loss, loss of appetite, and any cough there was no positive family history of breast tuberculosis or cancer. On local examination of right breast we had an breast enlargement with orange peel appearance and no lump was identified, an homolateral axillary lymphadenopathy of size $2 \mathrm{~cm}$ non-tender freely mobile suggesting a locally advanced breast cancer was recognized, the left breast was without abnormality as was the rest of the clinical examination.

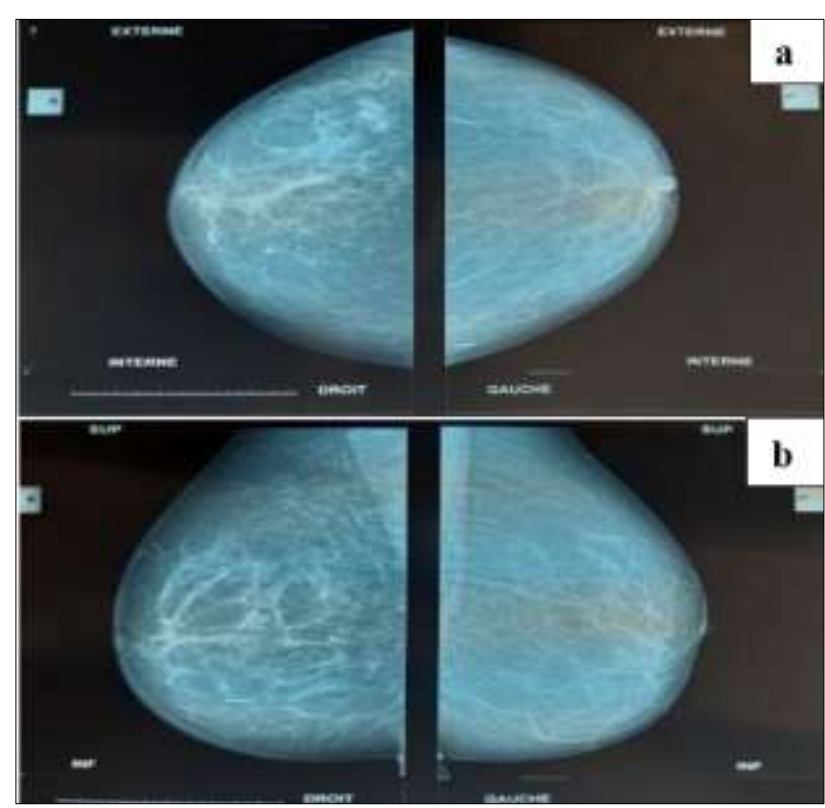

Figure 1: The mammography imaging of dense right breast with thickened skin. 


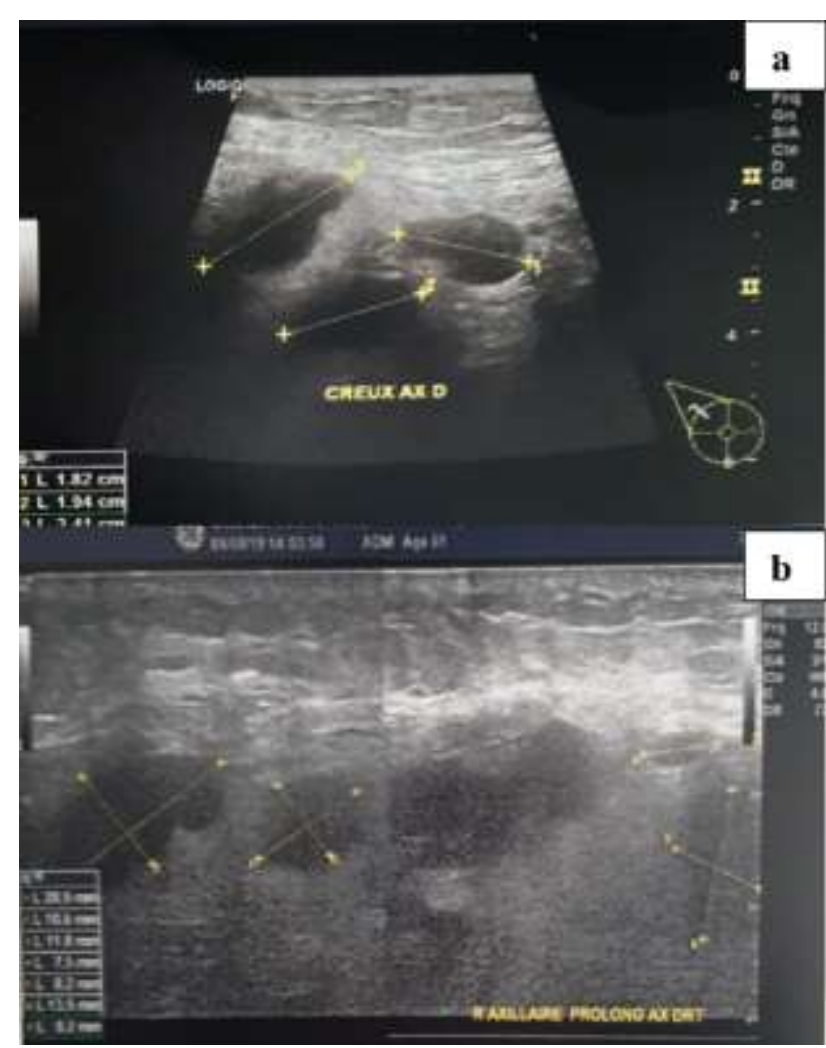

Figure 2: Ultrasound imaging of right axillary hollow and it's extension of lymphadenopathy.

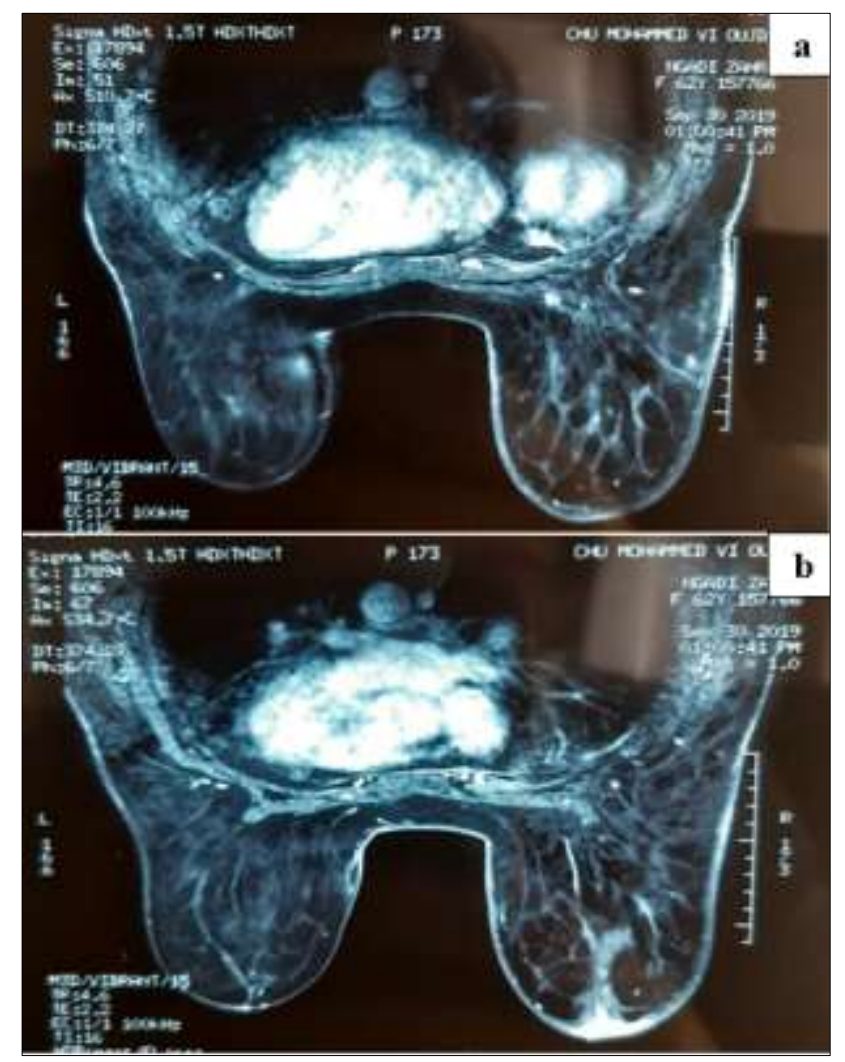

Figure 3: RIM T2 sequence revelling some focus associated with a thickening and enhancement of the areolo-mammalian plate.
The breast mammography (Figure 1) shows dense breast with thickened skin ultrasound imaging (Figure 2) revels multiple lymphadenopathies in axillary extension and axillary hollow of variable size, strongly hypo echogenic with regular outline and sometimes speculate, the largest of which is $21 / 11 \mathrm{~mm}$ classed BIRADS 4 .

On RIM (Figure 3), the breast was classified BIRADS5 because of the infiltrated aspect of the gland which is the seat of the abnormality of the linear signal and of some focus associated with a thickening and enhancement of the areolo-mammalian plate, right axillary lymphadenopathy of the axillary extension and the internal breast chain.

A skin biopsy shows nonspecific chronic inflammatory changes so we completed with a right lymphadenectomy which showed specific granulomatous chronic lymphadenitis with necrosis.

She was put on a 6-month course of anti-tubercular therapy with a 2-month intensive phase of rifampicin, isoniazid, ethambutol, and pyrazinamide followed by a consolidation phase of rifampicin and isoniazid for another 4 months. The orange peel appearance disappeared and the size of the breast become similar to the contralateral one.

\section{DISCUSSION}

Breast tuberculosis is a very rare form of tuberculosis. Its frequency varies from $0.06 \%$ to $0.1 \%$ of tuberculosis patients. ${ }^{1-3}$ Sir Astley Cooper in 1829 was the first one who recorded the first case of mammary tuberculosis and called it "Scrofulous swelling of the bosom."4

It occurs more frequently in females especially in their reproductive age and is uncommon in prepubescent and elderly women. ${ }^{5}$ Pregnancy, lactation and multiparity are risk factors due to galactophoric ectasia during lactation. ${ }^{5}$

\section{The infection can spread by different ways ${ }^{3}$}

- Hematogeneous: in the case of tuberculous military

- lymphatic, an axillary lymphadenopathy is often found

- Contiguous propagation

- ductal infection, the dilation of the milk ducts in women during pregnancy or breastfeeding increases the sensitivity of these ducts to infection by bacilli

- The direct route: exceptional, it is the penetration of the Koch bacillus into the breast following a cutaneous or galactophoric abrasion.

Breast TB may be considered primary when no other demonstrable focus exists, and may be considered secondary when a pre-existing lesion is located elsewhere. ${ }^{6}$ This case is a primary breast tuberculosis because there was no evidence of another focus on 
physical or radiological examination nor there was prior history of tuberculosis.

Fever, weight loss, night sweats, or failing of general health as constitutional symptoms of tuberculosis are infrequently found in the series by Khanna et al, Shinde et al and Harris et al. ${ }^{7-9}$ The most commonly Clinical presentations of tubercular infection of the breast the form of a lump or an inflammatory mass mimicking breast cancer. ${ }^{10}$ The lump can be fluctuated and is usually covered with indurated tissue. It is usually fixed to the skin and fistulation are frequent and oranges peel is often seen in patients with extensive axillary nodal tuberculosis. It can be suspected within the existence of rebellious recurrent abscess to antibiotics. ${ }^{11}$

There are no specific mammographic signs of mammary tuberculosis, mammography can show irregular heterogeneous opacities, not well limited with sometimes calcifications pointing rather towards a malignant etiology. ${ }^{12,13}$ On ultrasound, breast tuberculosis often appears in the form of a hypoechogenic, heterogeneous image, well or poorly limited, with minimal posterior reinforcement.

The positive diagnosis is based on histological study of biopsy of breast lump, ulcer, sinus, or from the wall of a suspected tubercular breast abscess cavity and identification of a characteristic epithelioid cell granulomas with necrosis. ${ }^{14}$

Medical therapy is the mainstay of therapy with antituberculous therapy.

\section{CONCLUSION}

Tuberculosis mastitis is a rare disease usually simulating breast cancer or breast abscess. The diagnosis is difficult due to the low clinical evidence and the lack of specificity of the imaging results. Presence of epithelial granulomas with caseous necrosis on histology is confirmatory. Treatment of breast tuberculosis consists of antitubercular drugs.

Funding: No funding sources Conflict of interest: None declared

Ethical approval: Not required

\section{REFERENCES}

1. De Sousa R, Patil R. Breast tuberculosis or granulomatous mastitis: a diagnostic dilemma. Ann Trop Med Public Health. 2011;4:122-5.

2. Gon S, Bhattacharyya A, Majumdar B, Kundu S. Tubercular mastitis-a great masquerade. Turk Patoloji Derg. 2013;29:61-3.

3. Hassouna JB, Gamoudi A, Bouzaiene H, Dhiab T, Khomsi F, Chargui R, et al. Tuberculose mammaire: étude retrospective de 65 case. Gynécol Obstét Fertil. 2005;33(11):870-6.

4. Cooper A. Illustration of the diseases of the breast: Part I. Longmans, Orme, London: Brown and Green; 1829:73.

5. Hamit HF, Ragsdale TH. Mammary tuberculosis. J R Soc Med. 1982;75:764-5.

6. McKeown KC, Wilkinson KW. Tuberculosis of the breast. Br J Surg. 1952;39:420-9.

7. Khanna R, Prasanna GV, Gupta P, Kumar M, Khanna S, Khanna AK. Mammary tuberculosis: report on 52 cases. Postgrad Med J. 2002;78:422-4.

8. Shinde SR, Chandawarkar RY, Deshmukh SP. Tuberculosis of the breast masquerading as carcinoma: a study of 100 patients. World J Surg. 1995;19:379-81.

9. Harris SH, Khan MA, Khan R, Haque F, Syed A, Ansari MM. Mammary tuberculosis: analysis of thirty-eight patients. ANZ J Surg. 2006;76:234-7.

10. Morsad F, Ghazli M, Boumzgou K, Abbassi H, El Kerroumi M, Matar N, et al. Mammary tuberculosis: a series of 14 cases. J Gynecol Obstet Biol Reprod. 2001;30:331-7.

11. Kalaç N, Ozkan B, Bayiz H, Dursun AB, Demirağ F. Breast tuberculosis. Breast. 2002;11:346-9.

12. Filippou DC, Rizos S, Nissiotis A. Primary breast tuberculosis. A case report. Radiol Oncol. 2003;37(1):1-3.

13. Mirsaeidi SM, Masjedi MR, Mansouri SD, Velayati AA. Tuberculosis of the breast: report of 4 clinical cases and literature review. Eas Mediter Health J. 2007;13(3):670-6.

14. Diesing D, Axt-Fliedner R, Hornung D, Weiss JM, Diedrich K, Friedrich M. Granulomatous mastitis. Arch Gynecol Obstet. 2004;269:233-6.

Cite this article as: Ennasser H, Raoudi JE, Taheri H, Saadi H, Mimouni A. Tuberculous mastitis: a rare case report. Int J Reprod Contracept Obstet Gynecol 2020;9:3909-11. 